\title{
Chronic nicotine ingestion and atrial fibrillation
}

\author{
P M STEWART, * J R CATTERALL $†$ \\ From the $\star$ Department for Metabolic and Endocrine Diseases, Western General Hospital, Edinburgh; and the fChest \\ Unit, City Hospital, Edinbrorgh
}

SUMmaRY Paroxysmal atrial fibrillation occurred in a fit 35 year old man who consumed large doses of nicotine chewing gum (Nicorette Leo) over a prolonged period.

Nicotine chewing gum was developed as an aid to smoking withdrawal and is usually effective in a dose of eight $2 \mathrm{mg}$ pieces daily. ${ }^{\prime}$ Reports of the cardiovascular effects of nicotine gum have been limited to an increase in heart rate, ${ }^{2}$ although nicotine has been shown to cause arrhythmias in animals. ${ }^{3}$ We report a patient who developed atrial fibrillation while consuming three to four times the usual amount of nicotine chewing gum.

\section{Case report}

A 35 year old man was admitted to hospital as an emergency, having been woken with prolonged periods of irregular palpitation. He denied chest pain or breathlessness but gave a one month history of similar periods of palpitation of shorter duration. For 18 months he had been trying to stop smoking (previously 40 cigarettes per day) and had been prescribed nicotine chewing gum (Nicorette Leo). Initially, he consumed 20 pieces of the $2 \mathrm{mg}$ gum daily, but two months before admission he had stopped smoking completely and increased his consumption to $30,2 \mathrm{mg}$ pieces, chewing each gum for at least 20 minutes. He chewed the gum almost continually. He drank one bottle of wine a day but did not drink spirits. There was no past history of rheumatic fever or scarlet fever and no family history of ischaemic heart disease or hyperlipidaemia.

Un admission he was in atrial fibrillation with an apical rate of 150 beats/min but was normotensive and had no signs of cardiac failure. He had no cardiac murmurs or pericardial friction rub, was clinically euthyroid, and remained apyrexial throughout admis-

Requests for reprints to Dr P M Stewart, Department for Endocrine and Metabolic Diseases, Western General Hospital, Crewe Road, Edinburgh EH4 2XU. sion. He was given digoxin and 24 hours later had reverted to sinus rhythm. Digoxin was stopped 24 hours later. Un three consecutive days the electrocardiogram and serum aspartate aminotransferase and lactate dehydrogenase activities were normal. Serum thyroxine and tri-iodothyronine concentrations, and thyrotropin releasing hormone stimulation test were normal, as were chest $x$-ray films, echocardiograms, full blood count, erythroctye sedimentation rate, plasma electrolyte concentrations, serial viral titres, and fasting concentrations of glucose, cholesterol, and triglycerides. The patient also had a normal exercise test (Bruce protocol) with no evidence of myocardial ischaemia. Plasma $\gamma$ glutamyl transferase activity was moderately increased at $90 \mathrm{u} / \mathrm{l}$ (normal 10-55 u/l), but bilirubin concentrations and serum alanine aminotransferase and alkaline phosphatase activities were normal. Blood nicotine concentration five hours after waking with palpitation (14 hours after the last Nicorette gum) was $4.8 \mathrm{ng} / \mathrm{ml}$.

He was reviewed at one, two, six, and 12 months, during which time he abstained from cigarette smoking and Nicorette consumption but continued to drink one bottle of wine a day. At one month a 24 hour ambulatory electrocardiogram was normal and at six months blood nicotine was undetectable, the plasma $\gamma$ glutamyl transferase activity remaining unchanged at $100 \mathrm{u} / \mathrm{l}$. To date he has had no further episodes of palpitation.

\section{Discussion}

The temporal relation between Nicorette (Leo) consumption and palpitation in our patient suggests a causal link between the two. He may have been predisposed to arrhythmias by drinking a bottle of wine a day, but his consumption of alcohol and the plasma $\gamma$ glutamyl transferase activity did not change over a 12 
month follow up period when he was free of palpitation.

After chewing nicotine gum the peak blood concentration of nicotine is no higher than after smoking cigarettes.' Even in habitual smokers, however, blood nicotine is undetectable eight hours after stopping smoking. ${ }^{4}$ In contrast, we detected nicotine in our patient 14 hours after chewing his last piece of nicotine gum. Thus a day to day accumulation of nicotine appears to be a potential risk when nicotine gum is chewed in large quantities. The effects of long term nicotine poisoning in man are unknown, ${ }^{5}$ but it is possible that atrial fibrillation in our patient was a manifestation of chronic nicotine intoxication.

We thank Dr R F Robertson, Royal Infirmary, Edinburgh, for allowing us to report his patient and Dr
Colin Feyerabend, for performing nicotine assays.

\section{References}

1 Russell MAH, Raw M, Jarvis $M J$. Clinical use of nicotine chewing gum. Br Med f 1980; 280: 1599-602.

2 Nyberg G, Panfilov V, Sivertsson R, Willhelmsen L. Cardiovascular effect of nicotine chewing gum in healthy non-smokers. Eur f Clin Pharmacol 1982; 23: 303-7.

3 Chevalier HJ, Kuhnigk C, Bandilla B, Dontenwill W, Hanel J. Effect of high doses of nicotine in pigs. I. Changes of the electrocardiogram. Basic Res Cardiol 1976; 71: 68-75.

4 Isaac PF, Rand MJ. Cigarette smoking and plasma levels of nicotine. Nature 1972; 236: 308-10.

5 Cohen AJ, Roe FJC. Monograph on the pharmacology and toxicology of nicotine. London: Tobacco Advisory Council, Occasional Paper 4, 1981. 